J. Dairy Sci. 97:5521-5532

http://dx.doi.org/10.3168/jds.2014-8093

(c) American Dairy Science Association ${ }^{\circledR}, 2014$.

\title{
Prepartum stocking density: Effects on metabolic, health, reproductive, and productive responses
}

\author{
P. R. B. Silva, ${ }^{\star} \dagger$ A. R. Dresch, ${ }^{*}$ K. S. Machado, ${ }^{*}$ J. G. N. Moraes, ${ }^{*}$ K. Lobeck-Luchterhand,† T. K. Nishimura, ${ }^{*}$ \\ M. A. Ferreira, ${ }^{*}$ M. I. Endres, $\dagger$ and R. C. Chebel ${ }^{*} \dagger^{1}$ \\ *Department of Veterinary Population Medicine, and \\ †Department of Animal Science, University of Minnesota, St. Paul 55108
}

\section{ABSTRACT}

The objectives of the current experiment were to determine the effects of 2 prepartum stocking densities on milk yield, concentration of metabolites during the peripartum period, and health and reproductive parameters of dairy cows. Jersey cows enrolled in the experiment at $254 \pm 3 \mathrm{~d}$ of gestation were balanced for parity (nulliparous vs. parous) and previous lactation projected 305-d mature equivalent milk yield (parous) and assigned to 1 of 2 treatments: $80 \%$ headlock stocking density (80SD; 38 animals/48 headlocks) and 100\% headlock stocking density (100SD; 48 animals/48 headlocks). The number of experimental units was 8 (4 replicates and 2 pens/ treatment per replicate). In total, 154 nulliparous and 184 parous animals were enrolled in the 80SD treatment and 186 nulliparous and 232 parous animals were enrolled in the 100SD treatment. At the start of each replicate, treatments were switched within pen. Cows were milked thrice daily and monthly milk yield, fat and protein content, and somatic cell count data were recorded up to $155 \mathrm{~d}$ postpartum. Plasma nonesterified fatty acid concentration was measured weekly, from $-18 \pm 3$ to $17 \pm 3 \mathrm{~d}$ relative to calving, and plasma $\beta$-hydroxybutyrate was measured weekly, from $1 \pm 2$ to $17 \pm 3 \mathrm{~d}$ relative to calving. Cows were examined 1,4 $\pm 1,7 \pm 1,10 \pm 1$, and $13 \pm 1 \mathrm{~d}$ relative to calving for diagnosis of uterine diseases. Blood was sampled for determination of progesterone concentration and resumption of ovarian cycles $35 \pm 3$ and $45 \pm 3$ d relative to calving. Average headlock (74.1 \pm 0.4 vs. $94.5 \pm 0.3 \%$ ) and stall $(80.8 \pm 0.4$ vs. $103.1 \pm 0.4 \%)$ stocking density was lower for the 80SD treatment compared with the 100SD treatment. Treatment did not affect incidence of retained fetal membranes $(80 \mathrm{SD}=5.1,100 \mathrm{SD}=7.8 \%)$, metritis $(80 \mathrm{SD}=21.2,100 \mathrm{SD}=16.7 \%)$, acute metritis $(80 \mathrm{SD}=9.9,100 \mathrm{SD}=9.4 \%)$, and vaginal purulent discharge $(80 \mathrm{SD}=5.8,100 \mathrm{SD}=7.9 \%)$. Concentrations of

Received February 28, 2014.

Accepted April 15, 2014.

${ }^{1}$ Corresponding author: chebe002@umn.edu nonesterified fatty acids $(80 \mathrm{SD}=251.5 \pm 6.1,100 \mathrm{SD}=$ $245.9 \pm 5.6 \mu \mathrm{mol} / \mathrm{L})$ and $\beta$-hydroxybutyrate $(80 \mathrm{SD}=$ $508.2 \pm 14.3,100 \mathrm{SD}=490.9 \pm 13.6 \mu \mathrm{mol} / \mathrm{L}$ ) were not different between treatments. Treatment had no effect on percentage of cows removed from the herd on the first $60 \mathrm{~d}$ postpartum $(80 \mathrm{SD}=6.1,100 \mathrm{SD}=5.1 \%)$ and on rate of removal from the herd up to $305 \mathrm{~d}$ postpartum $\{80 \mathrm{SD}=$ referent, 100SD [adjusted hazard ratio $(95 \%$ confidence interval $)]=1.02(0.75,1.38)\}$. Percentages of cows pregnant to first $(80 \mathrm{SD}=41.9,100 \mathrm{SD}=48.4 \%)$ and second $(80 \mathrm{SD}=49.3,100 \mathrm{SD}=42.0 \%)$ postpartum AI were not different between treatments. Finally, treatment did not affect energy-corrected milk yield up to $155 \mathrm{~d}$ postpartum $(80 \mathrm{SD}=33.8 \pm 0.5,100 \mathrm{SD}=33.4 \pm$ $0.5 \mathrm{~kg} / \mathrm{d}$ ). In herds with weekly or twice weekly movement of new cows to the prepartum pen and separate housing of nulliparous and parous animals, a target stocking density of $100 \%$ of headlocks on the day of movement is not expected to affect health, metabolic, reproductive, and productive parameters.

Key words: stocking density, prepartum cow

\section{INTRODUCTION}

Stocking density is an important topic for the dairy industry for several reasons. Changes in behavior are observed when stocking density is increased (Hosseinkhani et al., 2008; Proudfoot et al., 2009), raising issues regarding animal well-being. Two studies conducted at University of British Columbia demonstrated the effects of overstocking of prepartum cows on behavior and feed intake; elevated stocking density (2:1 vs. 1:1 cow to Insentec feed bin; Hosseinkhani et al., 2008) and feed bunk space (30 vs. $60 \mathrm{~cm} / \mathrm{cow}$; Proudfoot et al., 2009) resulted in increased rate of feed intake, fewer meals per day, increased feed sorting, decreased overall feed intake, increased standing time, and increased rate of displacement from the feed bunk (Hosseinkhani et al., 2008; Proudfoot et al., 2009). Furthermore, it has been suggested that increased stocking density limits normal variation in individual cow behavior (Ito et al., 2014). Because of the small number of experimental 
units used in most of these experiments, little is known about the effects of stocking density on health and performance.

The consequences of stocking density for dominant and submissive cows are likely to be distinct. Dominant cows may be predisposed to ruminal acidosis as a consequence of increased rate of feed intake, fewer meals per day, and increased feed sorting (Hosseinkhani et al., 2008). Conversely, submissive cows are more likely to have metabolic diseases, such as hepatic lipidosis and ketosis, because of reduced feed intake and ingestion of TMR previously sorted by dominant cows for more energy-dense ingredients, and to develop lameness because of increased standing time and displacement rate (Hosseinkhani et al., 2008; Proudfoot et al., 2009). This is particularly important when nulliparous and parous animals are housed together because nulliparous animals, which have a smaller frame and BW, are often submissive. In a study designed to evaluate the effects of a dietary supplement on productive and health parameters of prepartum nulliparous and parous animals housed together, it was observed that every 10 percentage unit increase in stocking density above $80 \%$ of headlocks resulted in a $0.7 \mathrm{~kg} / \mathrm{d}$ decrease in milk yield among first lactation cows (Oetzel et al., 2007). Even though this was not a study designed to evaluate the effect of stocking density on productive parameters, many have used this study as the basis for recommending that stocking density during the prepartum period should not exceed $80 \%$, particularly when heifers and cows are commingled.

The experiments cited previously were conducted with Holstein cows. To our knowledge, no experiments comparing the behavior of transition Holstein and Jersey cows under different managerial circumstances exists. A difficulty in commingling Holstein and Jersey cows to compare their behavior is the difference in body size, which is more likely to play a role in submissive and dominant behaviors than genetic composition of the cows. Nonetheless, differences in behavioral, immune, and neuroendocrine responses to stress may exist according to the genetic composition of the cows; therefore, the external validity of studies conducted with one breed to other breeds is questionable.

We hypothesized that increasing prepartum stocking density affects metabolic parameters and, consequently, affects health and productive parameters of peripartum dairy cows. The objectives of the current experiment were to determine the effect of increasing prepartum stocking density from 80 to $100 \%$ of headlocks on the day of regrouping on metabolic, health, reproductive, and productive parameters of first lactation and mature cows housed separately during the prepartum period.

\section{MATERIALS AND METHODS}

\section{Cows, Facilities, Management, and Nutrition}

The experiment was conducted from October 2012 to December 2013, with cows enrolled from October 2012 to February 2013 and calving occurring from October 2012 to March 2013. Prepartum Jersey animals were enrolled in the experiment at $254 \pm 3$ d of gestation. During the prepartum period, animals were separated by parity (nulliparous vs. parous) and housed in 1 of 4 freestall pens, with 44 stalls and 48 headlocks that were identical in size $\left(31.7 \times 11 \mathrm{~m}, 347.8 \mathrm{~m}^{2}\right)$ and design. Stalls measured 230 (length) $\times 107$ (width) $\times 114$ $\mathrm{cm}$ (neck rail height) and headlocks measured $61 \mathrm{~cm} /$ headlock. Pens had 2 water troughs at each end of the pen that measured 366 by $56 \mathrm{~cm}$. The barn was crossventilated and had artificial lighting.

As animals demonstrated signs of calving (discomfort, restlessness, tail twitching, and visualization of the allantoic sac through the vulva) they were moved to a boxstall. During the immediate postpartum period (1 to $21 \pm 3 \mathrm{DIM}$ ), cows were grouped by parity (primiparous vs. multiparous) and housed in freestall pens with 240 stalls and 260 headlocks. These pens had 5 water troughs per pen that measured 366 by 56 $\mathrm{cm}$. The barn was cross-ventilated and had artificial lighting (16 h of light and $8 \mathrm{~h}$ of dark). After calving, animals from different treatments were commingled in the same pen, but first lactation cows and mature cows were kept separate throughout lactation. From 1 to $21 \pm 3$ DIM, pens were stocked at 91.6 and $100 \%$ of headlocks and stalls, respectively. From $21 \pm 3$ DIM until diagnosis of pregnancy, at $66 \pm 3 \mathrm{~d}$ after AI, cows were housed in cross-ventilated freestall barns with 260 headlocks and 240 stalls. From the second pregnancy diagnosis to the end of the lactation, cows were housed in a nearby naturally ventilated freestall dairy (10 miles away) with 260 stalls and 280 headlocks. Stocking density from 21 DIM to the end of lactation varied between 110 and $120 \%$ of headlocks and between 119 and $130 \%$ of stalls.

A TMR was fed once a day from enrollment to calving. Primiparous and multiparous cows were fed the same TMR from 1 DIM until the time of the second pregnancy diagnosis, and primiparous and multiparous cows were fed the same TMR from the time of the second pregnancy diagnosis to drying off. Feed was delivered once a day during the winter and twice a day (70 and $30 \%$ for morning and afternoon feedings, respectively) during the summer for lactating cows. Composition of TMR fed in the prepartum and immediate postpartum ( 1 to $21 \pm 3$ DIM) periods are described in Table 1 . 
Table 1. Composition of TMR offered to far-off ( $\mathrm{d}-55 \pm 3$ to $-31 \pm 3$ relative to calving), close-up ( $\mathrm{d}-31 \pm 3$ to 0 relative to calving), and postpartum (d 1 to $21 \pm 3$ relative to calving) cows

\begin{tabular}{|c|c|c|c|c|c|c|}
\hline $\begin{array}{l}\text { Item, } \% \text { of DM } \\
\text { (unless otherwise indicated) }\end{array}$ & \multicolumn{3}{|c|}{ Parous } & \multicolumn{3}{|c|}{ Nulliparous } \\
\hline $\mathrm{NE}_{\mathrm{L}}, \mathrm{Mcal} / \mathrm{kg}$ & 1.45 & 1.39 & 1.64 & 1.37 & 1.43 & 1.65 \\
\hline $\mathrm{CP}$ & 15.05 & 14.62 & 19.49 & 14.38 & 14.98 & 17.64 \\
\hline $\mathrm{ADF}$ & 33.33 & 32.79 & 21.44 & 34.55 & 32.24 & 20.66 \\
\hline NDF & 47.05 & 47.38 & 32.40 & 49.83 & 47.66 & 32.93 \\
\hline Calcium & 0.91 & 1.24 & 1.03 & 0.99 & 0.81 & 1.08 \\
\hline Phosphorus & 0.33 & 0.33 & 0.42 & 0.34 & 0.36 & 0.48 \\
\hline Magnesium & 0.42 & 0.35 & 0.35 & 0.40 & 0.36 & 0.35 \\
\hline Potassium & 1.46 & 1.09 & 1.40 & 1.47 & 1.19 & 1.25 \\
\hline Sulfur & 0.25 & 0.31 & 0.30 & 0.25 & 0.26 & 0.31 \\
\hline Sodium & 0.23 & 0.15 & 0.47 & 0.23 & 0.13 & 0.37 \\
\hline Chlorine & 0.60 & 0.97 & 0.48 & 0.62 & 0.47 & 0.33 \\
\hline
\end{tabular}

\section{Treatments}

At enrollment, animals were balanced for parity (nulliparous or parous) and previous lactation 305-d mature equivalent milk yield (parous) and were assigned to 1 of the 4 study pens. Treatment applied to the study pens in the first replicate was determined by a coin toss. Animals were assigned to either the $80 \%$ headlock stocking density (80SD; $\mathrm{n}=2$ pens and 4 replicates) or $100 \%$ headlock stocking density (100SD; $\mathrm{n}=2$ pens and 4 replicates). Twice a week thereafter, groups of 2 to 15 cows (median $=9$ cows) were moved to the 80SD and 100SD pens to reestablish the desired stocking density. At the start of each replicate and on the days of movement of new cows to the study pens, the desired stocking densities were $80 \%$ of headlocks, $86.3 \%$ of stalls, and $9.2 \mathrm{~m}^{2} /$ cow for the 80SD treatment and $100 \%$ of headlocks, $109 \%$ of stalls, and $7.2 \mathrm{~m}^{2} /$ cow for the 100SD treatment.

At the end of each replicate, a new 80SD and 100SD group started but pens were switched to avoid location bias, even though pens were identical in design and had similar temperature and humidity throughout the study (data not shown). A total of 8 replicates (4 replicates and 2 pens/treatment per replicate) were used in the current study. Thus, each pen had the 80SD and 100SD treatments twice during the experiment. The number of cows in each pen was counted twice daily during the prepartum period by study personnel, and daily stocking density was calculated as the number of cows in the pen divided by the number of headlocks or stalls.

\section{Body Condition and Locomotion Score}

At enrollment and $1 \pm 1,35 \pm 3$, and $56 \pm 3$ DIM, all cows were scored for body condition $(1=$ emaciated and $5=$ obese; 0.25-unit increments, as described by Ferguson et al., 1994) and locomotion $(1=$ normal locomotion and $5=$ severely lame; as described by Sprecher et al., 1997). Cows with locomotion scores $\geq 3$ were considered lame.

\section{Blood Sampling and Analysis of Metabolites in Plasma}

Blood samples were collected from all cows at -17 $\pm 3,-11 \pm 3,-4 \pm 3,1 \pm 1,10 \pm 3$, and $17 \pm 3 \mathrm{~d}$ relative to calving from the coccygeal vein or artery immediately after feeding while cows were restrained in self-locking headlocks. The needles used were 22 gauge and 1 in long, and samples were collected into evacuated tubes containing K2 EDTA (Becton Dickinson Vacutainer Systems, Franklin Lakes, NJ). The utmost care was taken to minimize stress during sample collection. Tubes were placed in ice until centrifugation for plasma separation $\left(1,200 \times g\right.$ for $15 \mathrm{~min}$ at $\left.4^{\circ} \mathrm{C}\right)$. Plasma was aliquoted into microcentrifuge tubes and stored at $-32^{\circ} \mathrm{C}$ until analysis.

Samples collected weekly from $-17 \pm 3$ to $17 \pm 3$ $\mathrm{d}$ relative to calving were analyzed for concentrations of NEFA using a colorimetric assay (Wako Chemicals USA, Richmond, VA; Ballou et al., 2009). Concentrations of BHBA were determined enzymatically (Ranbut, Randox Laboratories, Antrim, UK; Ballou et al., 2009) from samples collected weekly from $1 \pm 1$ to 17 \pm 3 DIM. A plate reader (Spectramax 340, Molecular Devices, Sunnyvale, CA) was used to measure the absorbance for the colorimetric and enzymatic assays. Control serum (Randox Control Sera) was used for the NEFA and BHBA assays. The intraassay CV were 6.1 and $9.8 \%$ for the NEFA and BHBA assays, respectively. The interassay CV were 8.9 and $11.8 \%$ for the NEFA and BHBA assays, respectively. 


\section{Clinical Examination and Definitions of Diseases}

All cows were examined at $1,4 \pm 1,7 \pm 1,10 \pm 1$, and $13 \pm 1$ DIM for diagnosis of retained fetal membrane, metritis, and acute metritis. Retained fetal membrane was defined as retention of fetal membrane past $24 \mathrm{~h}$ postpartum. Metritis was defined as cows with watery, pink or brown, and fetid uterine discharge. Cows with symptoms of metritis, rectal temperature $>39.5^{\circ} \mathrm{C}$, or anorectic, or depressed were considered to have acute metritis (LeBlanc, 2010). All cows were examined for vaginal purulent discharge (VPD; formerly known as clinical endometritis) using the Metricheck device (Simcro, New Zealand; McDougall et al., 2007) at $35 \pm$ 3 DIM, and cows with $\geq 50 \%$ of pus in the exudate were considered positive for VPD.

All cows were observed once daily for displacement of abomasum and thrice daily for mastitis throughout their lactation. Data regarding incidence of displacement of abomasum and mastitis from 0 to 60 DIM are reported herein. Cows were followed from 0 to 305 DIM to determine the percentage of cows removed (sold or dead) from the herd and the speed at which cows were removed from the herd.

\section{Resumption of Ovarian Cycles Postpartum}

Blood was sampled on $35 \pm 3$ and $45 \pm 3$ DIM for determination of progesterone concentration by RIA using a commercial kit (Coat-a-Count Progesterone, Siemens Medical Solutions Diagnostics, Los Angeles, $\mathrm{CA}$ ). Cows with at least one sample with progesterone concentration $\geq 1 \mathrm{ng} / \mathrm{mL}$ were considered to have resumed their estrous cycle.

\section{Production Parameters}

Cows were milked thrice daily. Monthly, milk yield, milk fat and protein content, and SCC were recorded for individual cows during the official DHIA test. Data regarding milk yield, milk fat and protein content, and SCC were collected from 0 to 155 DIM. The DHIA testing ceased in August 2013; therefore, it was not possible to collect production data for the entire lactation. Energy-corrected milk was calculated for each cow using the formula (Orth, 1992)

$$
\begin{gathered}
\operatorname{ECM}(\mathrm{kg})=[(\mathrm{kg} \text { of milk }) \times 0.327]+[(\mathrm{kg} \text { of fat }) \\
\times 12.95]+[(\mathrm{kg} \text { of protein }) \times 7.2] .
\end{gathered}
$$

All cows received recombinant bST (500 mg of Posilac; Elanco Animal Health, Greenfield, IN) every $10 \mathrm{~d}$ starting at $57 \pm 3 \mathrm{~d}$ postpartum.

\section{Reproductive Management, Reproductive Parameters, and Removal from the Herd}

All cows were subjected to the same reproductive program. Cows were presynchronized with 3 injections of $\mathrm{PGF}_{2 \alpha}$ given on $39 \pm 3,53 \pm 3$, and $67 \pm 3$ DIM. Throughout the experiment, cows were observed daily for signs of estrus (removal of tail paint) and inseminated the same morning if observed in estrus after 50 DIM. Cows not observed in estrus were enrolled in the 5-d Cosynch protocol (GnRH, 5 d later $\mathrm{PGF}_{2 \alpha}, 24 \mathrm{~h}$ later $\mathrm{PGF}_{2 \alpha}$, and $72 \mathrm{~h}$ later $\mathrm{GnRH}$ and timed $\mathrm{AI}$ ) at $79 \pm 3 \mathrm{DIM}$ and were inseminated at fixed time, $87 \pm$ 3 DIM.

Cows not reinseminated in estrus were presented for pregnancy diagnosis by ultrasound ( $5 \mathrm{MHz}$ probe, E.I. Medical, Loveland, CO) at $31 \pm 3 \mathrm{~d}$ after AI, and pregnant cows were reexamined at $66 \pm 3$ and $178 \pm 3$ $\mathrm{d}$ after AI by manual palpation of the uterine contents per rectum. Cows diagnosed open were submitted to 1 of 2 resynchronization protocols. Nonpregnant cows with a corpus luteum received a $\mathrm{PGF}_{2 \alpha}$ injection $33 \pm 3$ $\mathrm{d}$ after AI, and, if not reinseminated in estrus by $45 \pm 3$ d after AI, were submitted to the 5-d Cosynch protocol and reinseminated at a fixed time, $53 \pm 3 \mathrm{~d}$ after AI. Nonpregnant cows without a corpus luteum received a GnRH injection $31 \pm 3 \mathrm{~d}$ after AI, and, if not reinseminated in estrus by $38 \pm 3 \mathrm{~d}$ after AI, were submitted to the 5-d Cosynch protocol and reinseminated at fixed time $46 \pm 3 \mathrm{~d}$ after AI.

From October 2012 to April 2013, only nonsexed semen was used for all inseminations of all cows. Starting in May 2013, sexed semen was used for insemination of cows observed in estrus (first and second postpartum $\mathrm{AI}$ ), whereas nonsexed semen was used for insemination of cows at a fixed time (first and second postpartum AI). Throughout the experiment, semen from 23 different sires (15 nonsexed and 8 sexed) were used for first and second postpartum AI. Farm personnel responsible for estrus detection and AI were blinded to treatments.

Percentage of cows receiving first AI in estrus, percentage of cows pregnant to first and second AI, and percentage of cows with pregnancy loss from $31 \pm 3$ to $66 \pm 3 \mathrm{~d}$ after first and second AI were calculated. Interval from calving to conception and interval from calving to removal from the herd were calculated for individual cows. For purposes of statistical analysis of interval from calving to conception, cows were right censored when they did not conceive and left the herd (died or sold) before $305 \mathrm{~d}$ of lactation or when they reached $305 \mathrm{~d}$ of lactation without conceiving. Conversely, for purposes of statistical analysis of interval from calving to removal from the herd, cows were right censored when they were dried off (approximately 220 
d of gestation) and when they reached 305 d of lactation.

\section{Statistical Analysis}

The experiment had a randomized switch-back design with pen as the experimental unit. Four replicates were used, and within each replicate 2 pens were used per treatment, resulting in 8 experimental units per treatment. In the first replicate, pens were blocked by parity (nulliparous and parous), a coin was tossed to determine the treatment of each of the 4 study pens. In each of the replicates cows were balanced for parity (nulliparous or parous) and previous lactation 305-d mature equivalent milk yield (parous), then, within parity, cows were assigned to 1 of the 4 study pens. Based on data from a previous experiment conducted in the same herd, the expected average and standard deviation of monthly ECM yield from calving up to $155 \mathrm{~d}$ postpartum were 33.5 and $2.0 \mathrm{~kg} / \mathrm{d}$, respectively. Thus, a total of 8 replicates were necessary to detect statistical significance $(\alpha=0.05, \beta=0.20)$ when the difference in average ECM yield in the first $155 \mathrm{~d}$ postpartum is $2.4 \mathrm{~kg} / \mathrm{d}$. Similarly, based on previous experiments conducted in the same herd, the average and standard deviation NEFA concentrations in the first $21 \mathrm{~d}$ postpartum were 320 and $9.5 \mu \mathrm{mol} / \mathrm{L}$, respectively. Therefore, a total of 8 replicates were necessary to detect statistical significance $(\alpha=0.05, \beta=0.20)$ when the difference in average NEFA concentration in the first $21 \mathrm{~d}$ postpartum is $11 \mu \mathrm{mol} / \mathrm{L}$.

All statistical analyses were conducted using SAS version 9.2 (SAS/STAT, SAS Institute Inc., Cary, NC). To ensure that cows subjected to different treatments and used in different replicates did not differ, data regarding age at enrollment, lactation number at enrollment, days of gestations (at enrollment and calving), BCS at enrollment, interval from enrollment to calving, previous lactation 305-d mature equivalent milk yield, and previous lactation interval from calving to conception were analyzed by ANOVA (PROC GLIMMIX) with a model that included treatment (80SD vs. 100SD), replicate (1 to 4 ), and, when appropriate, parity (nulliparous vs. parous). Age at enrollment, days of gestation at enrollment, and previous lactation interval from calving to conception did not have a normal distribution; therefore, statistical analysis was performed on logarithmic values and results are presented as back-transformed logarithmic values. Incidence of male calves and twin calving were analyzed by logistic regression (PROC LOGISTIC) with a model that included treatment (80SD vs. 100SD), replicate (1 to 4 ), and parity (nulliparous vs. parous).
Binomial dependent variables were analyzed by logistic regression using the GLIMMIX procedure with a binary distribution. Continuous data were analyzed by ANOVA using the GLIMMIX procedure with a normal distribution. Repeated measurements were analyzed by ANOVA for repeated measures using the MIXED procedure. The structure of covariance (autoregressive, unstructured, or compound symmetry) was chosen according to the Bayesian Akaike information criteria. In all models, treatment (80SD vs. 100SD), replicate (1 to 4 ), and parity (nulliparous vs parous) were included as fixed effects, pen was included as the random effect, and cows were nested within replicate and pen. For analysis of repeated measurements variables, time and the interaction between treatment and time were included in the model as fixed effects. Only the independent variables with $P<0.10$ were retained in the model.

Additional independent variables offered to the model to evaluate the effects of treatment on percentage of cows receiving first postpartum AI in estrus and DIM at first postpartum AI were parity, calf sex (male vs. female), twin calving (singleton vs. twin), and stillbirth (alive vs. dead). Additional independent variables offered to the model to evaluate the effect of treatment on pregnancy to first and second postpartum AI were parity, calf sex (male vs. female), twin calving (singleton vs. twin), stillbirth (alive vs. dead), AI protocol (estrus vs. timed AI), and semen (conventional vs. sexed). Interval from first to second postpartum AI and DIM at second postpartum AI did not have a normal distribution; therefore, statistical analysis was performed on logarithmic values and results are presented as backtransformed logarithmic values. Only the independent variables with $P<0.10$ were retained in the model.

The rate at which cows were removed from the herd was analyzed by Cox proportional hazard ratio using the PHREG procedure with removal of variables by a stepwise backward elimination process based on the Wald's statistics criterion when $P>0.10$. The model included treatment (80SD vs. 100SD), replicate (1 to 4), parity (nulliparous vs. parous), calf sex (male vs. female), twin calving (singleton vs. twin), and stillbirth (alive vs. dead) as fixed effects. Cow was used as the experimental unit in the Cox proportional hazard ratio analysis. Kaplan-Meier survival analysis, using the LIFETEST procedure, was used to compare the interval from enrollment to removal from the herd between treatments. Because the Kaplan-Meier survival analysis is a univariable analysis, only the calculated means to occurrence of the event are presented herein. Statistical significance was defined as $P \leq 0.05$ and statistical tendencies as $0.05<P \leq 0.10$. 


\section{RESULTS}

Thirteen 80SD heifers (8.4\%), one 80SD cow (0.6\%), thirteen 100SD heifers (6.6\%), and one 100SD cow $(0.4 \%)$ initially enrolled in the experiment did not calve within $35 \mathrm{~d}$ after enrollment and were subsequently diagnosed not pregnant and sold. Therefore, data presented herein is referent to 324 of the 80SD animals (141 nulliparous, 183 parous) and 404 of the 100SD animals (173 nulliparous, 231 parous).

At enrollment, days of gestation tended $(P=0.07)$ to be shorter for 80SD cows compared with 100SD cows $(253.9 \pm 1.0$ vs $254.2 \pm 1.0 \mathrm{~d})$. At enrollment, age $(80 \mathrm{SD}=31.2 \pm 1.0 \mathrm{mo}, 100 \mathrm{SD}=31.0 \pm 1.0 \mathrm{mo} ; P=$ $0.66)$, lactation number $(80 \mathrm{SD}=1.04 \pm 0.07$ lactation, $100 \mathrm{SD}=1.01 \pm 0.06$ lactation; $P=0.75)$, and BCS $(80 \mathrm{SD}=3.06 \pm 0.02,100 \mathrm{SD}=3.06 \pm 0.01 ; P=0.90)$ were not different between treatments. Among cows, treatments did not differ regarding previous lactation $305-\mathrm{d}$ mature equivalent milk yield $(80 \mathrm{SD}=10,252 \pm$ $127.3 \mathrm{~kg}, 100 \mathrm{SD}=10,246 \pm 110.3 \mathrm{~kg} ; P=0.97)$ and previous lactation interval from calving to conception $(80 \mathrm{SD}=82.9 \pm 1.0 \mathrm{~d}, 100 \mathrm{SD}=79.6 \pm 1.0 \mathrm{~d} ; P=$ $0.31)$.

Interval from enrollment to calving was not $(P=$ 0.27 ) different between treatments $(80 \mathrm{SD}=27.6 \pm$ $0.4 \mathrm{~d}, 100 \mathrm{SD}=27.0 \pm 0.4 \mathrm{~d})$. Upon calving, gestation length was not $(P=0.60)$ different between treatments $(80 \mathrm{SD}=281.5 \pm 0.4 \mathrm{~d}, 100 \mathrm{SD}=281.2 \pm 0.4 \mathrm{~d}) . \mathrm{In}-$ cidence of male calves was not $(P=0.49)$ different among nulliparous $(80 \mathrm{SD}=32.6 \%, 100 \mathrm{SD}=36.1 \%)$ and parous $(80 \mathrm{SD}=54.9 \%, 100 \mathrm{SD}=53.7 \%)$ cows assigned to the different treatments. Incidence of twin births also was not $(P=0.93)$ different among nulliparous $(80 \mathrm{SD}=0.7 \%, 100 \mathrm{SD}=0 \%)$ and parous $(80 \mathrm{SD}=$ $5.2 \%, 100 \mathrm{SD}=4.4 \%)$ cows assigned to the 80SD and 100SD treatments.

Daily average stocking densities based on number of headlocks $(80 \mathrm{SD}=74.1 \pm 0.4 \%, 100 \mathrm{SD}=94.5 \pm 0.3 \%$; $P<0.01)$ and stalls $(80 \mathrm{SD}=80.8 \pm 0.4 \%, 100 \mathrm{SD}=$ $103.1 \pm 0.4 \%$; $P<0.01)$ were different between treatments (Figure 1). Average temperature humidity index did not differ across the 4 study pens (average \pm SD $=$ $17.1 \pm 14.9$, range $=3.3-59.4$ ).

\section{Incidence of Diseases Postpartum}

Incidences of peripartum diseases were not different between 80SD and 100SD treatments (Table 2). Similarly, incidences of displacement of abomasum and mastitis in the first $60 \mathrm{~d}$ postpartum were not affected by treatment (Table 2). Percentages of cows with locomotion score $>2$ at $1 \pm 1,35 \pm 3$, and 56 $\pm 3 \mathrm{~d}$ postpartum were not different between treatments (Table 2). Similarly, treatment did not affect the likelihood of cows being removed from the herd within $60 \mathrm{~d}$ postpartum (Table 2). The rate at which cows in the 100SD treatment were removed from the herd [adjusted hazard ratio $(95 \% \mathrm{CI})=1.02(0.75,1.38)]$ did not $(P=0.90)$ differ from that of cows in the 80SD treatment. The mean $( \pm \mathrm{SEM})$ intervals from calving to removal from the herd were $258.3 \pm 4.5 \mathrm{~d}$ for the $80 \mathrm{SD}$ treatment and $262.5 \pm 3.9 \mathrm{~d}$ for the 100SD treatment (Figure 2).

\section{BCS and Metabolic Parameters}

Body condition score was not affected by treatment (Figure 3). Concentrations of NEFA (80SD $=251.5 \pm$ $6.1,100 \mathrm{SD}=245.9 \pm 5.6 \mu \mathrm{mol} / \mathrm{L}$ ) was not different between treatments (Figure 4). Similarly, concentration of BHBA $(80 \mathrm{SD}=508.2 \pm 14.3,100 \mathrm{SD}=490.9 \pm 13.6$ $\mu \mathrm{mol} / \mathrm{L}$ ) was not different between treatments (Figure $5)$.

\section{Resumption of Ovarian Cycles Postpartum and Reproductive Parameters}

The percentages of cows characterized as cyclic by 35 \pm 3 and $45 \pm 3$ DIM were not different between treatments (Table 3). Similarly, the likelihood of cows being inseminated in estrus and the DIM at first postpartum AI were not different between treatments (Table 3). The percentages of cows diagnosed as pregnant at 31 \pm 3 and $66 \pm 3 \mathrm{~d}$ after first postpartum AI were not different between treatments (Table 3 ). Incidence of pregnancy loss between $31 \pm 3$ and $66 \pm 3 \mathrm{~d}$ after first postpartum AI was not different between treatments (Table 3). The interval from first to second postpartum $\mathrm{AI}$ and the DIM at second postpartum AI were not different between 80SD and 100SD treatments (Table 3 ). The percentages of cows diagnosed pregnant $31 \pm 3$ and $66 \pm 3 \mathrm{~d}$ after the second postpartum AI were not different between 80SD and 100SD treatments (Table 3). Similarly, incidence of pregnancy loss between $31 \pm$ 3 and $66 \pm 3 \mathrm{~d}$ after the second postpartum AI was not affected by treatment (Table 3 ).

\section{Milk Yield and Milk Components}

Average daily milk yield from calving to 155 DIM was not different between treatments (Table 4). Similarly, fat and protein yield were not different between 80SD and 100SD cows (Table 4). Consequently, yield of 3.5\% FCM and ECM were not different between treatments (Table 4; Figure 6). 
Table 2. Effects of prepartum stocking density on incidence of postpartum health disorders, lameness, and removal from the herd within $60 \mathrm{~d}$ postpartum

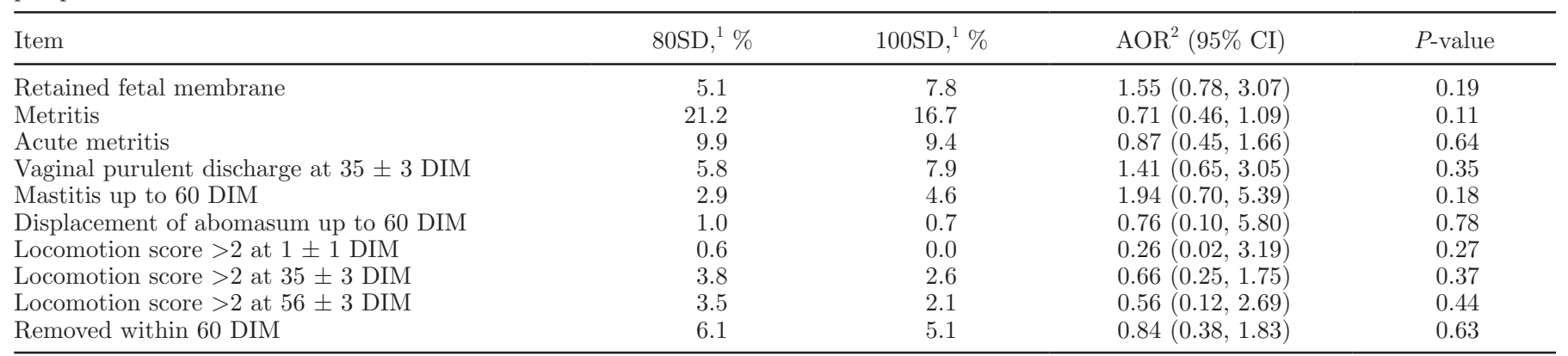

${ }^{1} 80 \mathrm{SD}=$ cows housed in prepartum pens with $80 \%$ target headlock stocking density $(38 / 48) ; 100 \mathrm{SD}=$ cows housed in prepartum pens with $100 \%$ target headlock stocking density $(48 / 48)$.

${ }^{2} \mathrm{AOR}=$ adjusted odds ratio. The 80SD treatment was set as referent.

\section{DISCUSSION}

The stocking densities on the day of regrouping of the current experiment were based on the commonly recommended stocking density of $80 \%$ of headlocks. Because stocking density of prepartum pens is dynamic and dependent on number of cows calving per day, the average daily stocking densities were 74.1 and $94.5 \%$ of headlocks for 80SD and 100SD treatments, respectively, despite the fact that new cows were moved into the prepartum pen twice weekly. The stocking densities based on number of stalls, however, were 80.8 and $103.1 \%$ for the 80SD and 100SD treatments, respectively. Industry standards suggest that prepartum headlock stocking density $>80 \%$ may affect the performance of postpartum cows. No controlled experiments demonstrating

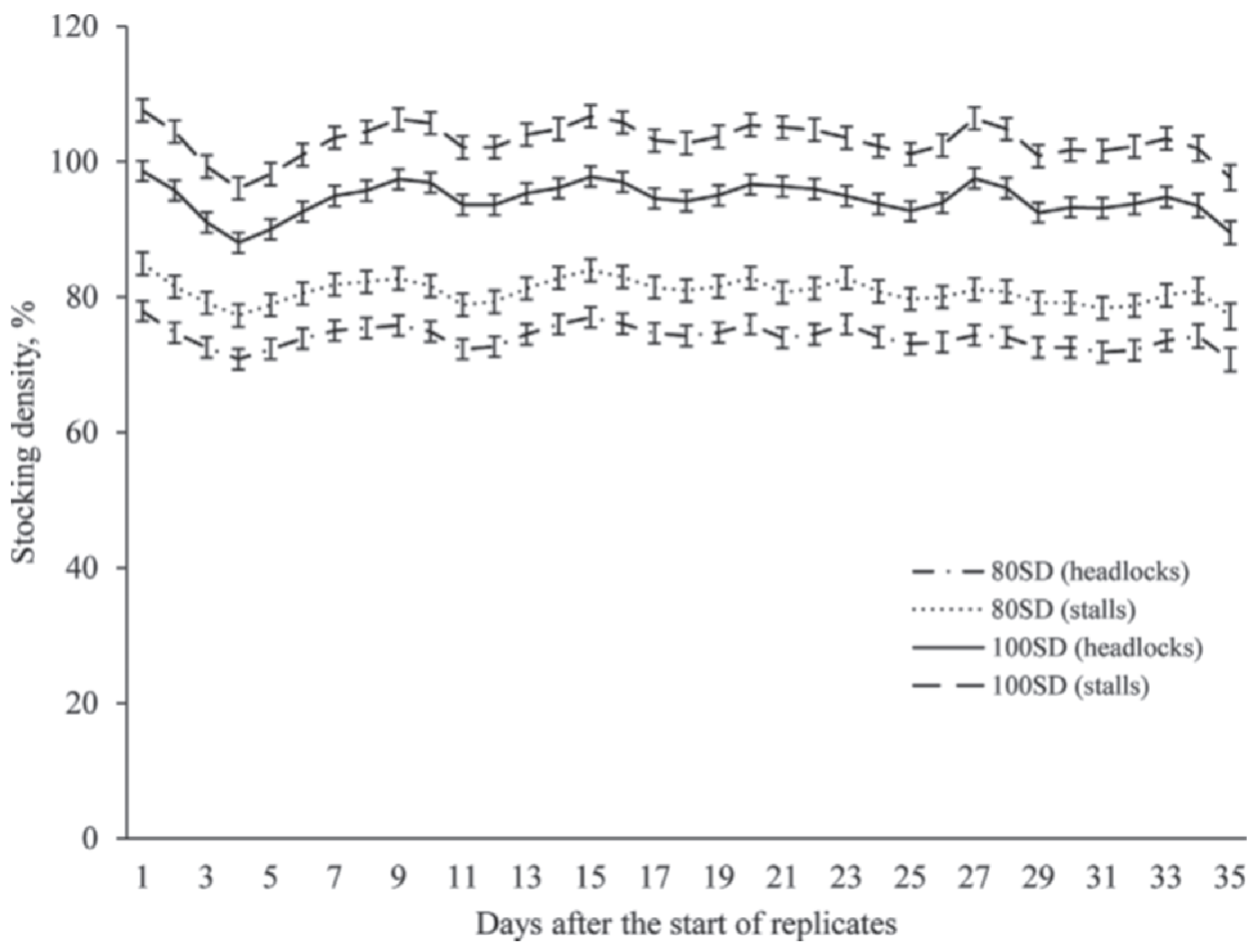

Figure 1. Stocking density based on headlocks and stalls according to treatments. $80 \mathrm{SD}=$ cows housed in prepartum pens with $80 \%$ target headlock stocking density (38/48); 100SD = cows housed in prepartum pens with $100 \%$ target headlock stocking density (48/48). Treatment affected the mean $( \pm$ SEM $)$ stocking densities based on number of headlocks $(80 \mathrm{SD}=74.1 \pm 0.4 \%, 100 \mathrm{SD}=94.5 \pm 0.3 \% ; P<0.01)$ and stalls $(80 \mathrm{SD}=80.8 \pm 0.4 \%, 100 \mathrm{SD}=103.1 \pm 0.4 \% ; P<0.01)$. 


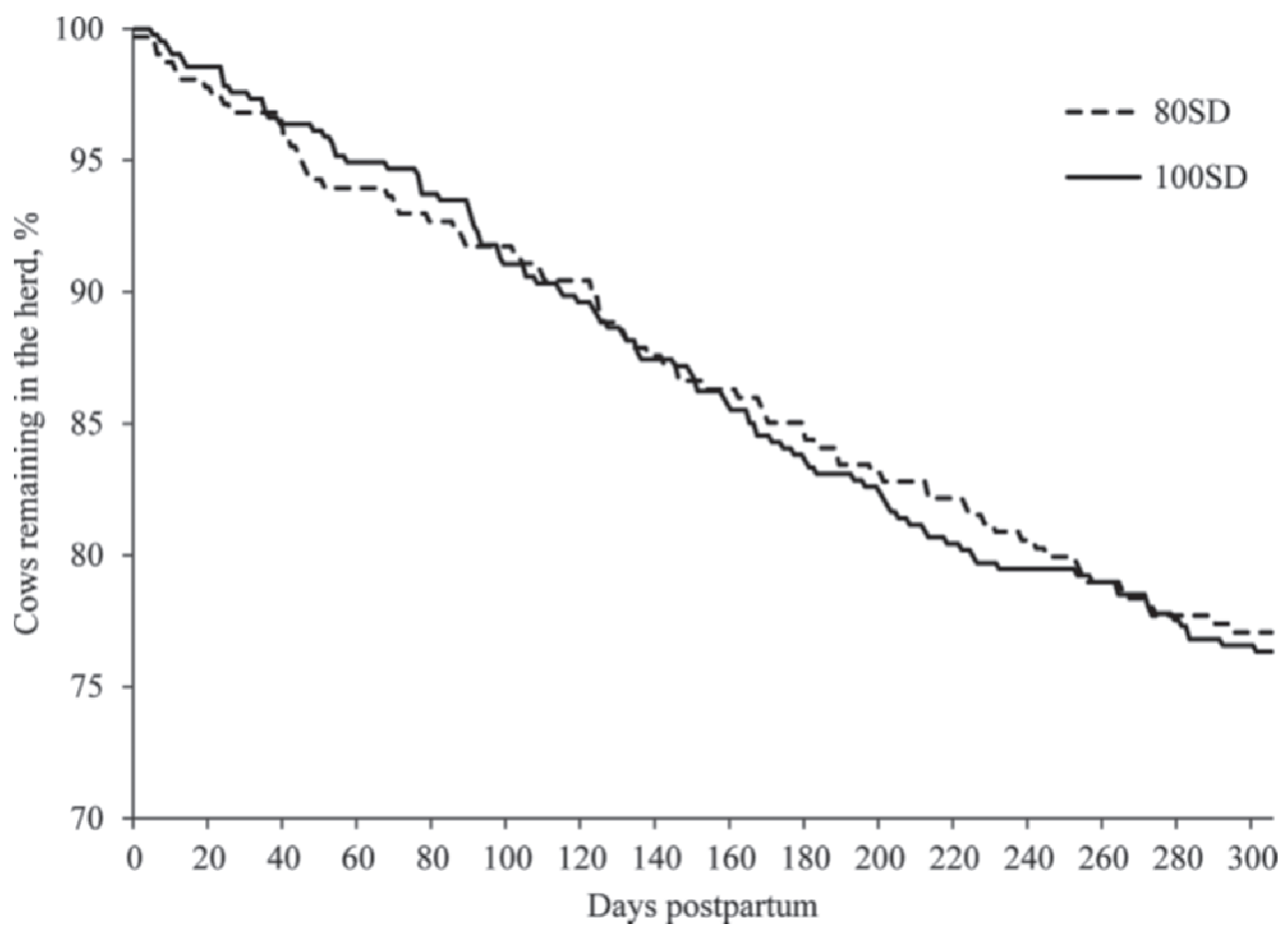

Figure 2. Survival analysis of interval from calving to removal from the herd according to prepartum stocking density. The adjusted hazard ratio (AHR) for removal from the herd was not $(P=0.90)$ different between the cows housed in prepartum pens with $100 \%$ target headlock stocking density [100SD; AHR $(95 \%$ CI $)=1.02(0.75,1.38) ; 48 / 48]$ and cows housed in prepartum pens with $80 \%$ target headlock stocking density (80SD; 38/48). The mean ( \pm SEM) intervals from calving to removal from the herd were $258.3 \pm 4.5 \mathrm{~d}$ for the $80 \mathrm{SD}$ treatment and 262.5 $\pm 3.9 \mathrm{~d}$ for the 100SD treatment.

the effects of stocking density on productive or health parameters had been conducted to date, however. Thus, the recommendation of $80 \%$ headlock stocking density may have been adopted based on the findings of Oetzel et al. (2007). In that experiment, which was designed

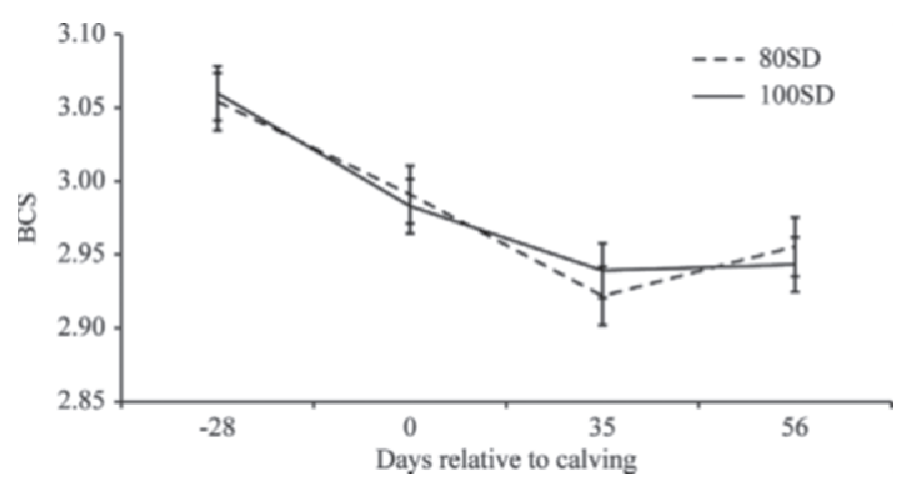

Figure 3. Body condition score of cows housed in prepartum pens with $80 \%$ target headlock stocking density (80SD; 38/48) and cows housed in prepartum pens with $100 \%$ target headlock stocking density (100SD; 48/48). Treatment $(P=0.97)$ and the interaction between treatment and days relative to calving $(P=0.66)$ did not affect BCS throughout the study.

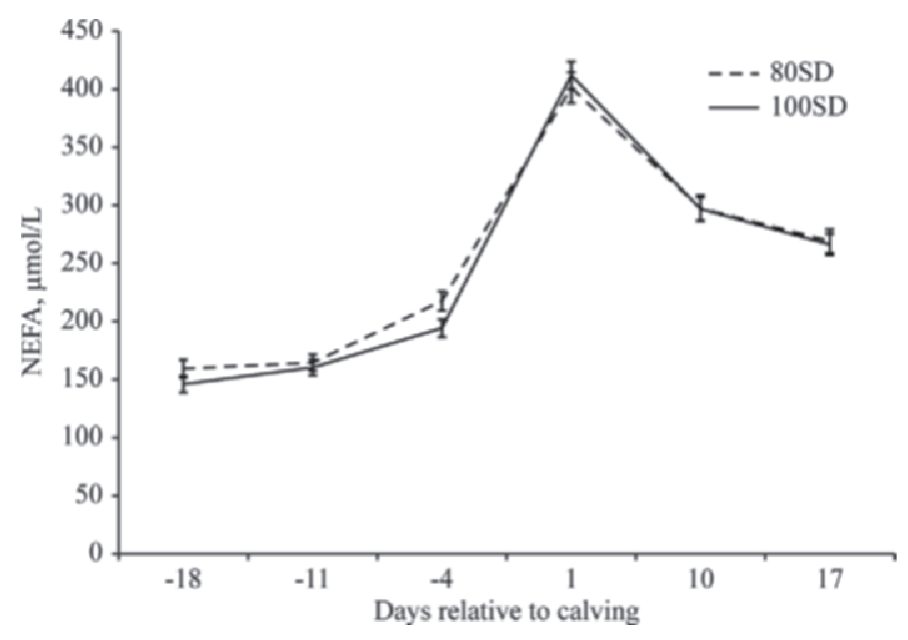

Figure 4. Mean $( \pm \mathrm{SEM})$ plasma concentrations of NEFA of cows submitted to different prepartum stocking density. 80SD = cows housed in prepartum pens with $80 \%$ target headlock stocking density $(38 / 48) ; 100 \mathrm{SD}=$ cows housed in prepartum pens with $100 \%$ target headlock stocking density $(48 / 48)$. No effects of treatment $(P=0.51)$ and of the interaction between treatment and days relative to calving $(P=0.32)$ on NEFA concentrations were observed. 


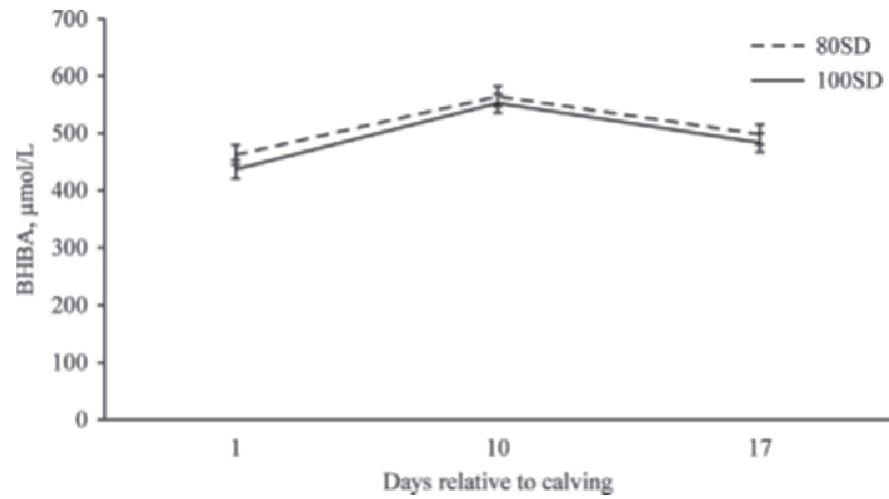

Figure 5. Mean $( \pm$ SEM $)$ plasma concentrations of BHBA of cows submitted to different prepartum stocking density. 80SD = cows housed in prepartum pens with $80 \%$ target headlock stocking density $(38 / 48) ; 100 \mathrm{SD}=$ cows housed in prepartum pens with $100 \%$ target headlock stocking density $(48 / 48)$. No effects of treatment $(P=0.40)$ and of the interaction between treatment and days relative to calving $(P=0.83)$ on BHBA concentrations were observed.

to evaluate the effects of a prepartum feed additive on performance of lactating dairy cows, the authors determined, retrospectively, that for every $10 \%$ increase in prepartum stocking density above $80 \%$ a $0.7 \mathrm{~kg} / \mathrm{d}$ decrease in milk yield of primiparous cows between 5 and 85 DIM was expected (Oetzel et al., 2007). Because this was not a controlled experiment to evaluate the effects of prepartum stocking density on performance, it is possible that differences in prepartum stocking density were associated with seasonal variation in number of calving, confounding the results of the experiment (Oetzel et al., 2007). Furthermore, nulliparous and parous animals were housed together (Oetzel et al., 2007).

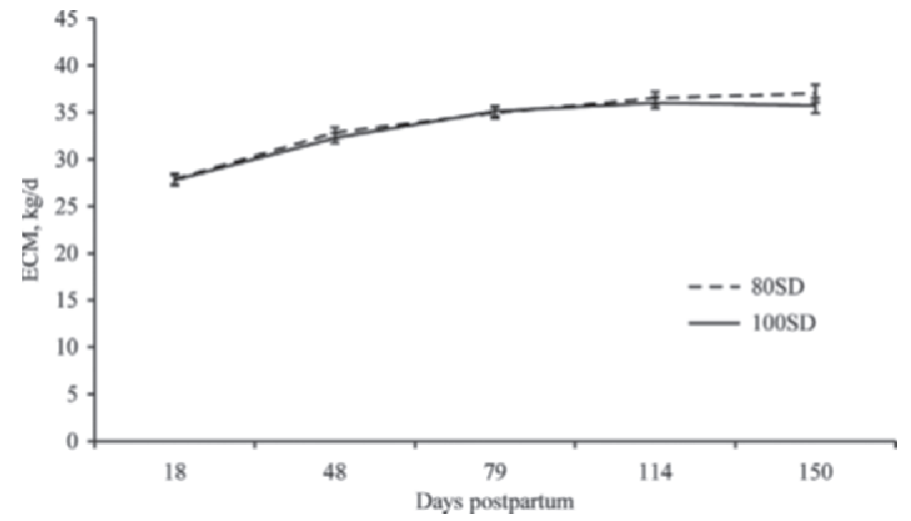

Figure 6. Yield of ECM according to prepartum grouping strategy. $80 \mathrm{SD}=$ cows housed in prepartum pens with $80 \%$ target headlock stocking density $(38 / 48) ; 100 \mathrm{SD}=$ cows housed in prepartum pens with $100 \%$ target headlock stocking density $(48 / 48)$. No effect of treatment $(P=0.54)$ or interaction between treatment and month of lactation $(P=0.69)$ on yield of ECM was observed.

Therefore, it is not surprising that stocking density was associated with milk yield of nulliparous animals, which are smaller and more likely to be submissive than parous animals. In the current experiment, nulliparous and parous animals were housed separately. Although many herds commingle nulliparous and parous animals, our objective was to evaluate the effect of prepartum stocking density under management conditions that would be considered ideal (e.g., separation of nulliparous and parous animals, sufficient water availability, deepbedded stalls, and so on). Therefore, the findings of the current experiment may not be easily extrapolated to herds with inadequate management.

Table 3. Effects of prepartum stocking density on resumption of ovarian cycles postpartum, estrus expression, percentage of cows pregnant after first and second postpartum AI, and number of inseminations

\begin{tabular}{|c|c|c|c|c|}
\hline Item & $80 \mathrm{SD}^{1}$ & $100 \mathrm{SD}^{1}$ & $\operatorname{AOR}^{2}(95 \% \mathrm{CI})$ & $P$-value \\
\hline Cows cyclic by 35 DIM, ${ }^{3} \%$ & 45.5 & 48.2 & $1.19(0.72,1.95)$ & 0.47 \\
\hline Cows cyclic by 45 DIM, ${ }^{3} \%$ & 60.0 & 66.3 & $1.30(0.67,2.55)$ & 0.40 \\
\hline \multicolumn{5}{|l|}{ First postpartum AI } \\
\hline DIM $( \pm$ SEM $)$ & $57.4 \pm 2.5$ & $56.7 \pm 2.4$ & NA & 0.73 \\
\hline Pregnant at $31 \pm 3 \mathrm{~d}, \%$ & 46.6 & 52.6 & $1.18(0.83,1.67)$ & 0.33 \\
\hline Pregnant at $66 \pm 3 \mathrm{~d}, \%$ & 41.9 & 48.4 & $1.23(0.87,1.74)$ & 0.23 \\
\hline Pregnancy loss from $31 \pm 3$ to $66 \pm 3 \mathrm{~d}, \%$ & 8.7 & 6.8 & $0.82(0.26,2.57)$ & 0.72 \\
\hline DIM $( \pm \text { SEM })^{4}$ & $100.0 \pm 1.0$ & $98.0 \pm 1.0$ & NA & 0.47 \\
\hline Pregnant at $31 \pm 3 \mathrm{~d}, \%$ & 52.9 & 46.3 & $0.74(0.44,1.26)$ & 0.25 \\
\hline Pregnant at $66 \pm 3 \mathrm{~d}, \%$ & 49.3 & 42.0 & $0.72(0.43,1.21)$ & 0.20 \\
\hline Pregnancy loss from $31 \pm 3$ to $66 \pm 3 \mathrm{~d}, \%$ & 5.1 & 7.6 & $1.47(0.31,6.98)$ & 0.61 \\
\hline
\end{tabular}

${ }^{1} 80 \mathrm{SD}=$ cows housed in prepartum pens with $80 \%$ target headlock stocking density $(38 / 48) ; 100 \mathrm{SD}=$ cows housed in prepartum pens with $100 \%$ target headlock stocking density (48/48).

${ }^{2} \mathrm{AOR}=$ adjusted odds ratio. The $80 \mathrm{SD}$ treatment was set as referent.

${ }^{3}$ Cows cyclic by $35 \mathrm{DIM}=$ cows with progesterone concentration $>1 \mathrm{ng} / \mathrm{mL}$ at $35 \mathrm{DIM}$; cows cyclic by 45 DIM $=$ cows with progesterone concentration $>1 \mathrm{ng} / \mathrm{mL}$ at 35 or $45 \mathrm{DIM}$, or both.

${ }^{4}$ Values are back-transformed logarithmic values. 
Table 4. Monthly productive parameters and milk quality up to $155 \mathrm{~d}$ postpartum of cows submitted to different prepartum stocking densities

\begin{tabular}{lrrc}
\hline Item, $\mathrm{kg} / \mathrm{d}$ & \multicolumn{1}{c}{$80 \mathrm{SD}^{1}$} & \multicolumn{1}{c}{$100 \mathrm{SD}^{1}$} & $P$-value \\
\hline Milk yield & $28.49 \pm 0.53$ & $28.17 \pm 0.50$ & 0.68 \\
Fat yield & $1.33 \pm 0.02$ & $1.31 \pm 0.02$ & 0.47 \\
Protein yield & $1.01 \pm 0.02$ & $1.00 \pm 0.01$ & 0.85 \\
$3.5 \%$ FCM & $33.90 \pm 0.52$ & $33.39 \pm 0.48$ & 0.48 \\
ECM yield & $33.84 \pm 0.52$ & $33.39 \pm 0.48$ & 0.54 \\
\hline
\end{tabular}

${ }^{1} 80 \mathrm{SD}=$ cows housed in prepartum pens with $80 \%$ target headlock stocking density $(38 / 48) ; 100 \mathrm{SD}=$ cows housed in prepartum pens with $100 \%$ target headlock stocking density $(48 / 48)$.

Treatment did not affect metabolic status before calving, as observed by the similar NEFA concentrations from -18 to $17 \mathrm{~d}$ relative to calving and the similar BCS from -28 to 0 d relative to calving. Similarly, no differences were observed between treatments regarding postpartum NEFA and BHBA concentrations and BCS. Although we could speculate that DMI was not different between treatments because no differences were noted for metabolic parameters, ECM yield, and BCS, DMI data was not collected because the experiment was conducted in a commercial herd. Therefore, it is not possible to rule out differences in feed efficiency between treatments. Although we conclude that increasing prepartum headlock stocking density from 80 to $100 \%$ may not affect metabolic parameters of peripartum animals, it is not clear what the maximum acceptable stocking density during the prepartum period is. In a recent experiment, Huzzey et al. (2012) demonstrated that when nonlactating pregnant (214 d of gestation) nulliparous and parous animals housed together were exposed to $200 \%$ stocking density (1 vs. 2 cows/stall) behavioral and metabolic changes were observed. However, the effects of stocking density on behavior and metabolism were dependent on parity. Changes in stocking density from 100 to $200 \%$ increased the interval to approach the feed bunk among nulliparous animals, reduced the percentage of feeding time within $3 \mathrm{~h}$ of feed delivery among nulliparous and parous animals, and increased the number of displacements from the feed bunk (Huzzey et al., 2012). Although greater stocking density increased group DMI, elevated stocking density was associated with greater plasma NEFA and glucose concentrations and greater fecal cortisol concentration among nulliparous animals, but not parous animals (Huzzey et al., 2012). Based on the glucose tolerance test, those authors demonstrated that nulliparous and parous animals exposed to $200 \%$ stocking density were more likely to be resistant or desensitized to insulin (Huzzey et al., 2012). These are important metabolic alterations in prepartum animals that may have a profound effect on immune response and health parameters during the peripartum period.
In the current experiment, stocking density had no effect on incidence of uterine diseases. Actually, a large numerical difference was observed in incidence of metritis in favor of the 100SD treatment. This is surprising because one of the hypotheses of the current experiment was that reduced prepartum stocking density would result in reduced incidence of immune-related (e.g., retained fetal membranes) and infectious (e.g., metritis) diseases because of improved energy status during the peripartum period. Randomly selected subgroups of 80SD and 100SD animals were used to evaluate the effects of prepartum stocking density on immune parameters (Dresch et al., 2013). Stocking density did not affect PMNL count and PMNL phagocytic activity or oxidative burst (Dresch et al., 2013). Therefore, despite our initial hypotheses, it is not surprising that stocking density had no effect on incidence of retained fetal membranes, metritis, and VPD. The lack of difference in incidence of displacement of abomasum and the lack of differences on NEFA and BHBA concentration between treatments suggest that $100 \%$ prepartum stocking density did not affect the metabolism of peripartum cows compared with $80 \%$ prepartum stocking density. One of the initial hypotheses of the current experiment was that increased stocking density would increase incidence of lameness as a consequence of increased displacement from the feed bunk and decreased lying time (Proudfoot et al., 2009). Surprisingly, no effect of treatment was noted on percentage of cows with a locomotion score $>2$ at 0,35 , and 56 DIM despite the fact that during $47.8 \%$ of the prepartum period there were at least 2 or more cows than stalls in the 100SD treatment and during $100 \%$ of the prepartum period there were 4 fewer cows than stalls in the 80SD treatment. The lack of effect of stocking density on the percentage cows removed from the herd within 60 DIM and the lack of effect of stocking density on rate at which cows were removed from the herd up to 305 DIM reinforces the conclusion that stocking density had no effect on health status of peripartum cows in a situation in which heifers and cows were housed separately.

Because of the negative association between peripartum health and metabolic disorders and reproductive 
and productive performances, we hypothesized that animals in the 80SD treatment would have improved reproductive and productive performances. The close relationship between metabolic status and resumption of ovarian cycles postpartum (Butler, 2003), and the fact that treatment did not affect metabolic status peripartum, explains why incidences of cyclic cows at 35 and 45 DIM were similar between treatments. The lack of differences in reproductive parameters between treatments is likely a consequence of the lack of differences between treatments regarding the incidence of peripartum disorders and cyclicity at 35 and 45 DIM. Similarly, the lack of difference between treatments regarding productive performance is likely associated with the lack of difference between treatments regarding metabolic and health parameters. Furthermore, the nearly identical yield of ECM and metabolic parameters pre- and postpartum allows us to speculate that prepartum 100\% stocking density of headlocks on the day of regrouping does not affect energy status and feed intake. It is interesting that several studies have demonstrated that increasing stocking density affects feeding and lying behavior (Olofsson, 1999; DeVries and von Keyserlingk, 2006; Proudfoot et al., 2009), but because these experiments had a limited number of experimental units, effects of stocking density on health, reproductive, and productive parameters were not evaluated. Nonetheless, researchers continue to affirm that behavioral changes due to managerial changes warrant adoption of dramatically different management of dairy cows. In the current experiment, feeding, social, and lying behaviors of 80SD and 100SD animals were evaluated (Lobeck et al., 2013; K. M. Lobeck-Luchterhand, P. R. B. Silva, R. C. Chebel, and M. I. Endres, unpublished data). The 100SD treatment resulted in greater displacement from the feed bunk than the 80SD treatment independent of parity. Feeding time was reduced for nulliparous animals in the 80SD treatment compared with the 100SD treatment, but feeding time tended to be greater for parous animals in the 80SD treatment than those in the 100SD treatment (K. M. Lobeck-Luchterhand, P. R. B. Silva, R. C. Chebel, and M. I. Endres, unpublished data). Interestingly, stocking density had no effect on lying behavior of prepartum cows. These are important considerations because they demonstrate that increasing average daily stocking density by 20 percentage units (from 80 to 100\%) affected the social and feeding behavior of prepartum animals. Conversely, changes in behavior associated with elevated stocking density had no effect on metabolic status or health, reproductive, and productive parameters. In a recent experiment, we demonstrated that despite the fact that a stable prepartum pen (no entrance of new cows) reduces competition in the feed bunk, it had no positive effects on immune, metabolic, health, reproductive, or productive performances (Silva et al., 2013a, b). Thus, recommendations regarding management of dairy cows may not be based solely on their effects on the behavior of cows.

\section{CONCLUSIONS}

The current experiment compared stocking densities in a large dairy operation with a large number of animals. In situations in which management is adequate (e.g., separation of nulliparous and parous animals, adequate water availability, proper heat abatement, deep bedding), increasing prepartum stocking density on the day of regrouping from 80 to $100 \%$ of headlocks did not affect metabolic status and incidence of peripartum diseases. Consequently, reproductive and productive performances of animals exposed to $100 \%$ stocking density were not compromised compared with animals exposed to $80 \%$ stocking density. Recommendations, such as reduced prepartum stocking density, have a profound economic effect on dairy operations because of the increased fixed cost for building of facilities. Because minute behavioral alterations are not necessarily associated with changes in immune, metabolic, health, reproductive, and productive parameters, one may not base managerial recommendations solely on behavioral responses of dairy cows.

\section{ACKNOWLEDGMENTS}

The authors thank the owner, manager, and staff of New Sweden Dairy (Nicollet, MN). This experiment was partially funded by the Minnesota Agricultural Experiment Station (St. Paul) through Rapid Agriculture Response Fund grant.

\section{REFERENCES}

Ballou, M. A., R. C. Gomes, S. O. Juchem, and E. J. DePeters. 2009. Effects of dietary supplemental fish oil during the peripartum period on blood metabolites and hepatic fatty acid compositions and total triacylglycerol concentrations of multiparous Holstein cows. J. Dairy Sci. 92:657-669.

Butler, W. R. 2003. Energy balance relationships with follicular development, ovulation and fertility in postpartum dairy cows. Livest. Prod. Sci. 83:211-218.

DeVries, T. J., and M. A. G. von Keyserlingk. 2006. Feed stalls affect the social and feeding behavior of lactating dairy cows. J. Dairy Sci. 89:3522-3531.

Dresch, A. R., J. G. N. Moraes, P. R. B. Silva, H. Hooper, C. Spies, P. K. Lau, K. M. Lobeck, K. S. Machado, M. A. Ballou, M. I. Endres, and R. C. Chebel. 2013. Effect of stocking density in the prepartum period on innate immune parameters and hemogram of dairy cows. J. Dairy Sci. 96(E-Suppl. 1):46.

Ferguson, J. D., D. T. Galligan, and N. Thomsen. 1994. Principal descriptors of body condition score in Holstein cows. J. Dairy Sci. $77: 2695-2703$. 
Hosseinkhani, A., T. J. DeVries, K. L. Proudfoot, R. Valizadeh, D. M. Veira, and M. A. G. von Keyserlingk. 2008. The effects of feed bunk competition on the feed sorting behavior of close-up dry cows. J. Dairy Sci. 91:1115-1121.

Huzzey, J. M., D. V. Nydam, R. J. Grant, and T. R. Overton. 2012. The effects of overstocking Holstein dairy cattle during the dry period on cortisol secretion and energy metabolism. J. Dairy Sci. 95:4421-4433.

Ito, K., N. Chapinal, D. M. Weary, and M. A. G. von Keyserlingk. 2014. Associations between herd-level factors and lying behavior of freestall-housed dairy cows. J. Dairy Sci. 97:2081-2089.

LeBlanc, S. 2010. Monitoring metabolic health of dairy cattle in the transition period. J. Reprod. Dev. 56:S29-S35.

Lobeck, K. M., M. I. Endres, A. R. Dresch, and R. C. Chebel. 2013. Effect of feed bunk stocking density on lying behavior of dairy cows. J. Dairy Sci. 96(E-Suppl. 1):431.

McDougall, S., R. Macaulay, and C. Compton. 2007. Association between endometritis diagnosis using a novel intravaginal device and reproductive performance in dairy cattle. Anim. Reprod. Sci. 99:9-23.

Oetzel, G. R., K. M. Emery, W. P. Kautz, and J. E. Nocek. 2007. Direct-fed microbial supplementation and health and performance of pre- and postpartum dairy cattle: A field trial. J. Dairy Sci. 90:2058-2068.
Olofsson, J. 1999. Competition for total mixed diets fed for ad libitum intake using one or four cows per feeding station. J. Dairy Sci 82:69-79.

Orth, R. 1992. Sample day and lactation report. Dairy Herd Improvement Association 200 Fact Sheet A-2. Mid-States Dairy Records Processing Center (DRPC), Ames, IA.

Proudfoot, K. L., D. M. Veira, D. M. Weary, and M. A. G. von Keyserlingk. 2009. Competition at the feed bunk changes the feeding, standing and social behavior of transition dairy cows. J. Dairy Sci. 92:3116-3123.

Silva, P. R., J. G. Moraes, L. G. Mendonca, A. A. Scanavez, G. Nakagawa, M. A. Ballou, B. Walcheck, D. Haines, M. I. Endres, and R. C. Chebel. 2013a. Effects of weekly regrouping of prepartum dairy cows on innate immune response and antibody concentration. J. Dairy Sci. 96:7649-7657.

Silva, P. R. B., J. G. N. Moraes, L. G. D. Mendonça, A. A. Scanavez, G. Nakagawa, J. Fetrow, M. I. Endres, and R. C. Chebel. 2013b. Effects of weekly regrouping of prepartum dairy cows on metabolic, health, reproductive, and productive parameters. J. Dairy Sci. 96:4436-4446.

Sprecher, D. J., D. E. Hostetler, and J. B. Kaneene. 1997. A lameness scoring system that uses posture and gait to predict dairy cattle reproductive performance. Theriogenology 47:1179-1187. 